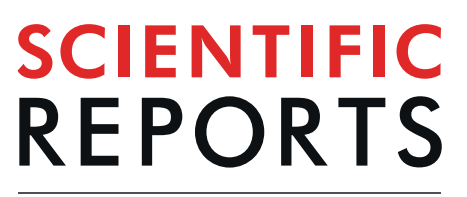

natureresearch

\title{
Detection and functional characterization of sigma class GST in Phlebotomus argentipes and its role in stress tolerance and DDT resistance
}

\author{
Faizan Hassan ${ }^{1}$, Krishn Pratap Singh ${ }^{2}$, Vahab Ali ${ }^{2 *}{ }^{*}$, Sachidananda Behera ${ }^{2}{ }^{2}$, \\ Pushkar Shivam ${ }^{3}$, Pradeep Das ${ }^{4}$ \& Diwakar Singh Dinesh ${ }^{1 *}$
}

Several Glutathione S-transferases (GSTs) enzymes, in insects, have previously been implicated in resistance developed against DDT and other insecticides. The GST enzyme particularly sigma class have important physiological role in detoxification of lipid peroxidation by-products in insects. Phlebotomus argentipes has been intensely exposed to DDT over years due to Indoor Residual Spray (IRS) programme for Kala-azar elimination in Bihar, India. However, in P. argentipes, role of GSTs in DDT resistance have not been elucidated. Here, sigma class GST of $P$. argentipes (Parg-GST $\sigma$ ) was successfully cloned, expressed and purified by affinity chromatography. The recombinant Parg-GST $\sigma$ was found to be highly active towards cumene hydroperoxide and 4-HNE having specific activity $92.47 \& 203.92 \mu \mathrm{M} / \mathrm{min} / \mathrm{mg}$ of protein, respectively and exhibited low activity towards universal substrate CDNB i.e., $8.75 \mu \mathrm{M} / \mathrm{min} /$ $\mathrm{mg}$ of protein. RT-PCR and immunoblot analysis showed at least 2 and 1.8 fold overexpression of PargGST $\sigma$ in the single exposed and non exposed DDT resistant $P$. argentipes as compared to susceptible, implicating Parg-GST $\sigma$ also involved in DDT resistance probably by imparting enhanced stress tolerance. The DDT, $\mathrm{H}_{2} \mathrm{O}_{2}$ and temperature induction assays demonstrated stress-dependent induction of Parg-GST $\sigma$ expression indicating its important role in oxidative stress redressal.

Leishmaniasis is one of the seven neglected tropical diseases identified by World Health Organization, exhibiting broad spectrum clinical manifestations with fatal outcome ${ }^{1}$. Approximately, 1.5 to 2 million new cases are reported each year and causes 70,000 deaths per year with an estimated population of 350 million at risk ${ }^{2}$. Visceral Leishmaniasis (VL) is the most severe form of leishmaniasis and it is estimated that more than $90 \%$ cases of VL occurs mainly in five countries: India, Bangladesh, Nepal, Sudan, and Brazil ${ }^{3}$. According to a recent report ${ }^{4}$, India hosts 5634 annual cases of VL and 1916 cases of Post-Kala-Azar Dermal Leishmaniasis (PKDL) which suggests that control of VL is still a major issue. Phlebotomus argentipes (sand fly) is an established vector of Kala-azar or VL in Indian subcontinent. In India, northeastern regions of Bihar and it's adjacent states like Jharkhand, West Bengal \& Uttar Pradesh are predominantly affected by this disease and were targeted for VL elimination by $2017^{5}$. Among the various factors perceived to be involved in lack of achieving the elimination target, development of insecticide resistance may be one of the prominent factors potentially capable of jeopardizing the elimination program. Insecticides are one of the major tools to control the vectors responsible for transmission of diseases in the world. However, prolong use of insecticides may lead to development of insecticide resistance and severely impede Kala-azar elimination program. Although alternative strategies like impregnated nets, environmental management etc. are also implemented for the control of vector density, the use of insecticides has most profound

\footnotetext{
${ }^{1}$ Department of Vector Biology \& Control, Rajendra Memorial Research Institute of Medical Sciences (ICMR), Agam Kuan, Patna, 800007, India. 'Laboratory of Molecular Biochemistry and Cell Biology, Department of Biochemistry, Rajendra Memorial Research Institute of Medical Sciences (ICMR), Agam Kuan, Patna, 800007, India. ${ }^{3}$ Department of Microbiology, Rajendra Memorial Research Institute of Medical Sciences (ICMR), Agam Kuan, Patna, 800007, India. ${ }^{4}$ Department of Molecular Biology, Rajendra Memorial Research Institute of Medical Sciences (ICMR), Agam Kuan, Patna, 800007, India. *email: vahab_ali@yahoo.com; drdsdinesh@yahoo.com
} 
impact in the elimination of vector-borne diseases. DDT was the first synthetic organochlorine insecticide to be discovered during the World War II and was extensively used all over the world in Malaria control program. Earlier, it showed quick knock down efficiency on insect vectors and longer residual effect up to 6 months (WHO Report 1997;http://www.who.int/water_sanitation_health/resources/vector357to384.pdf). However, its knock down efficiency has gradually reduced towards $P$. argentipes due to development of DDT resistance. In India, DDT was first employed in malaria control program launched in 1953 (WHO Report 1997; http://www.who.int/ water_sanitation_health/resources/ vector 357to384.pdf) and was later adopted in Kala-azar elimination program $^{5}$. However, despite continuous use of DDT in Indoor Residual Spray (IRS), Kala-azar is still prevalent in several districts of Bihar ${ }^{5,6}$. The failure in achieving Kala-azar elimination target 2017 in India may be due to irregularities in quality and frequency of DDT IRS ${ }^{7}$. Moreover, the same factor may be also implicated for gradual development of insecticide resistance ${ }^{8}$. DDT resistance not only impaired the IRS program but has also raised the possibility of resistance, phenotypic \& genotypic fixation in the sand flies. The phenotypic fixation may be seen in the form of tolerance developed against recently introduced Pyrethroid $\alpha$-Cypermethrin, whereas, genotypic fixation as knock-down resistance (Kdr) was reported in DDT resistant P. argentipes from Bihar9.

DDT resistance has been reported in many insects and more than one mechanism could be involved in acquisition of DDT resistance as reported previously in different studies on many insects ${ }^{10-12}$. Metabolic resistance caused by detoxifying enzymes has been widely accepted and well characterized in various insects including Drosophila and mosquitoes ${ }^{13-15}$. Among the various detoxifying enzymes involved in metabolic resistance, several classes of Glutathione S-transferase (GSTs; E.C.2.5.1.18) have been extensively explored in mosquitoes and were shown to mediate resistance by direct detoxification of DDT using GSH as cofactor ${ }^{12,16}$. GSTs are the major detoxification enzymes found in most organisms including insects. In vertebrates and non-vertebrates, GSTs are mainly involved in detoxification of xenobiotics, protection from oxidative damage by eliminating the by-products of oxidative stress ${ }^{17}$, intracellular transport of hormones and various endogenous metabolites ${ }^{18}$. The involvement of GSTs in insecticide resistance has been reported for organophosphates in house flies ${ }^{19}$, whereas, in many DDT resistant insects, including P. argentipes ${ }^{20}$, Anopheles gambiae ${ }^{21}$, Anopheles ageypti ${ }^{22}$, higher GSTs activity has been reported. Seven classes of GST are found in insects out of which only three classes, viz sigma ${ }^{23,24}$, delta ${ }^{25}$, and epsilon $^{26}$ have been shown to be involved in insecticide resistance. The delta and epsilon classes of GST metabolize DDT by dehydrochlorination and thus impart DDT resistance in insects (mosquitoes) ${ }^{27}$. However, sigma class GST has higher affinity to organophosphorus insecticide (Fenitrothion) and play important role in oxidative stress response in fall webworm ${ }^{23,24}$. However, till date, no reports are available regarding the characterization of any class of GST in DDT resistance in sand flies.

The induction of stress due to herbicides and insecticides exposure is well characterized and has been reported in many insect species ${ }^{28-30}$. Insect GSTs may contribute in defense against oxidative damage by detoxifying or scavenging the secondary product generated by ROS or by directly metabolizing 4-Hydroxy-nonenal (4-HNE), one of the end products of lipid peroxidation (LPO), through conjugation ${ }^{31}$. The physiological role of GSTs as antioxidant in response to oxidative stress was reported in several insects species like, Anopheles mosquitoes and Honey bee $\mathrm{b}^{32-34}$. The total GST activity was also found to be elevated in DDT resistant Anopheles arabiensis and Anopheles funestus strains to cope with oxidative stress ${ }^{35,36}$. Although, biochemical method for estimation and comparison of the activity of detoxifying enzymes including GSTs enzymes has been reported for insects including $P$. argentipes ${ }^{37,38}$ but this method cannot differentially elucidate or indicate the specific class of GST enzymes. Therefore, elucidating the role of specific class of GSTs is very crucial to understand the mechanism of detoxification and designing novel inhibitors for controlling $P$. argentipes population. The unavailability of genome database of $P$. argentipes poses a challenging task to pursue studies on specific genes including different classes of GSTs. In this study, we successfully cloned, expressed and purified the sigma class GST protein of $P$. argentipes and investigated its enzymatic properties and potential role in imparting DDT resistance in P. argentipes. Finally, we explored the potential role of sigma class GST as a diagnostic marker for differentiating DDT resistant and susceptible $P$. argentipes by utilizing the polyclonal antibodies raised against this purified protein and developing a modified $3,3^{\prime}$-diaminobenzidine (DAB) based assay ${ }^{39}$ to detect GST expression even in a single P. argentipes.

\section{Experimental Procedures}

Chemical and reagents. 1-chloro-2,4-dintrobenzene (CDNB), Anti-DNPH antibody, Reduced glutathione (GSH), Ethacrynic acid, Hydroxynonenal (4-HNE), Glutathione reductase, Dichlorodiphenyltrichloroethane (DDT) and Dichlorodiphenyldichloroethylene (DDE) were purchased from Sigma-Aldrich (USA). All other reagents used were of analytical grades.

Animal ethical statement. Female Balb/c mice were used for raising polyclonal antibody against purified, recombinant sigma GST protein and procedure used was reviewed and approved by Institutional Animal Ethical Committee (IAEC), Rajendra Memorial Research Institute of Medical Sciences, Patna, Indian Council of Medical Research, Government of India, New Delhi held on $14^{\text {th }}$ July 2017 vide no: INT-109/14.07.2017. All the methods used in the study were carried out according to the regulations and guidelines of the IAEC committee governed by CPCSEA, New Delhi, Government of India.

Tube-Bioassay test. DDT resistant $P$. argentipes is abundantly available in the adjoining areas of the study site and, therefore, raising a resistant colony is not much troublesome; because it has developed DDT resistance to various extents in almost all the endemic districts of Bihar covered under the DDT IRS program as reported previously $^{40}$. In contrast, there is no report of $100 \%$ susceptible $P$. argentipes field isolates from India in the recent years. To find susceptible $P$. argentipes, the Kaler village of Gaya district was chosen because in Kaler region, DDT or other insecticide has not been used in IRS for at least more than 5 years as per the information gathered from local villagers. So, we expected a higher probability of getting pure susceptible P. argentipes in Kaler. 
Tube bioassay is the primary assay recommended by WHO for determining phenotypic resistance in insects $^{34,38}$ including $P$. argentipes ${ }^{41,42}$. So, to access the susceptibility of Kaler $P$. argentipes, tube bioassay was conducted. Briefly, Kaler sandflies were collected through mechanical aspirator and field samples of female $P$. argentipes were segregated into 5 tubes of 20 sandflies each (5 replicates) and each tube was subjected to DDT exposure by confining them inside the tube containing 4\% DDT impregnated paper for $1 \mathrm{hr}$ exposure. After exposure period, each tube of sandflies was transferred to recovery tubes containing DDT control paper and recovery was assessed after $24 \mathrm{hrs}$. The knockdown percentage was calculated and plotted against the resistant sandflies subjected to identical tube bioassay. All sandflies $(n=100)$ died within $24 \mathrm{hrs}$. So, next time, we collected sandflies by mechanical aspirator from the same area for raising susceptible colony, and directly confined them inside Hilton pots for further generation of susceptible colony in our laboratory. In every generation susceptibility of sandflies was accessed through tube bioassay.

DDT has been replaced by $\alpha$-cypermethrin, a pyrethroid insecticide, for IRS program in the endemic regions due to emergence of DDT resistance. To keep the samples unbiased and essentially not intermingled with any insecticide other than DDT, Vikram village of Patna district was chosen because there was no previous history of IRS with any other insecticides except DDT in this village. To obtain DDT resistant sandfly, wild $P$. argentipes were collected from Vikram village in early morning (6 A.M. to 8 A.M.) with mechanical aspirator from April-June 2014 and subjected to identical tube bioassay as described above for susceptible sandflies. We observed that $>60 \%$ sandflies survived after tube assay. For raising DDT resistant colony, the Vikram sandflies surviving after tube bioassay were reared in the laboratory. The $100 \%$ pure DDT resistant sandflies were generated by exposing every generation with 4\% DDT and individually confining the live female P. argentipes in separate Hilton pots to get the pure colony of DDT resistant.

PCR amplification, cloning and expression of recombinant GST sigma gene (GST $\sigma$ ). The P. argentipes GST $\sigma$ gene specific primers were designed using P. papatasi GST $\sigma$ gene sequence as template. The primers used for PCR amplification were as follows: forward primer 5'-TGCTAGGATCCATGCCCAACTACAAAGTGATC-3' and reverse primer 5' - TAGGTAAGCTTTTAAACTTCAGTAACAGGTCG-3' with a BamH1 \& Hind III restriction sites (depicted in bold letters) in forward and reverse primer, respectively. Total RNA was isolated from the pool of 15 female DDT resistant sandflies using Trizol reagent according to manufacturer's protocol. The cDNA was synthesized using cDNA synthesis Kit (Thermo-Fisher) according to manufacturer's protocol. The GST $\sigma$ gene was PCR amplified from cDNA using Taq DNA polymerase and GST $\sigma$ gene specific primers. The PCR condition were $94^{\circ} \mathrm{C}$ for $6 \mathrm{~min}$ followed by 35 cycles of $94^{\circ} \mathrm{C}$ for $30 \mathrm{~s}, 55^{\circ} \mathrm{C}$ for $35 \mathrm{~s}, 72^{\circ} \mathrm{C}$ for $40 \mathrm{~s}$ and final extension at $72^{\circ} \mathrm{C}$ for $7 \mathrm{~min}$. The $612 \mathrm{bp} \mathrm{PCR} \mathrm{product} \mathrm{was} \mathrm{purified} \mathrm{from} 1 \%$ agarose gel using PCR product purification kit (Promega) and sequenced commercially (Xcelris, Ahmedabad, India). The obtained sequence was searched for homologous sequences using online BLAST tool and subjected to sequence alignment using Clustal W. For cloning, the PCR product was digested using restriction enzymes BamH1 and Hind III (Promega) as per the manufacturer's protocol. The purified digested product was then ligated into digested pET-28a expression/cloning vector using Ligation Kit (Promega) and transformed in E. coli DH5 $\alpha$ cells. The positive clones were purified using Plasmid purification Kit (Promega) and the insert was sequenced with T7 universal primer for pET-28a vector. For expression of recombinant GST $\sigma$ protein, the positive clone was transformed into E. coli BL21 (DE3) cells and expression was induced with $1.0 \mathrm{mM}$ IPTG at $30^{\circ} \mathrm{C}$ for $6 \mathrm{hrs}$.

Purification of recombinant P.argentipes GST $\sigma$ (rParg-GST $\sigma$ ). The induced GST $\sigma$ in E. coli BL-21 cells were harvested at $8000 \mathrm{x}$ g for $8 \mathrm{~min}$ and pellet corresponding to $50 \mathrm{ml}$ culture was resuspended in bacterial lysis solution ( $50 \mathrm{mM}$ Tris-Cl, $300 \mathrm{mM} \mathrm{NaCl}, 0.1 \%$ Triton X-100, and $10 \%$ Glycerol) supplemented with $100 \mu \mathrm{g} /$ $\mathrm{ml}$ lysozyme and $1 \mathrm{mM}$ PMSF. The cells were incubated for $20 \mathrm{~min}$ at $4{ }^{\circ} \mathrm{C}$ and $20 \mathrm{~min}$ at room temperature before sonicating the sample on ice. After centrifugation at $20,000 \mathrm{rpm}$ for $20 \mathrm{~min}$ at $4{ }^{\circ} \mathrm{C}$, the supernatant was collected and used for purification of recombinant rParg-GST $\sigma$ using $\mathrm{Ni}^{+2}$-NTA affinity chromatography (Thermo-Fisher) according to manufacturer's protocol. The elution of protein was performed with $100 \mathrm{mM}, 200 \mathrm{mM}, 300 \mathrm{mM}$, $400 \mathrm{mM}$ and $500 \mathrm{mM}$ imidazole gradient prepared in bacterial lysis buffer. The purified protein was analyzed on $12 \%$ SDS-PAGE and pure homogeneous fractions were pooled and dialyzed overnight at $4{ }^{\circ} \mathrm{C}$ in Phosphate buffer saline (pH-6.5) using dialysis membrane (Thermo-Fisher). The dialyzed protein was concentrated using $15 \mathrm{ml} 10$ MWK concentrator (Merck) and protein concentration was estimated spectrophotometrically at $595 \mathrm{~nm}$ using Bradford reagent (Sigma-Aldrich) following manufacturer's protocol; BSA was used as protein standard. The concentrated protein was used for performing enzyme assays and polyclonal antibody generation.

Enzyme assays. CDNB assay. GSTs help in cellular detoxification of xenobiotics by catalyzing the conjugation of reduced glutathione with electrophilic xenobiotics. CDNB is the universal electrophilic substrate of all classes of GST, although, each class may differ in their affinity or specific activity towards CDNB. Thus, to determine the enzyme characteristics of purified rParg-GST $\sigma$ protein against CDNB, CDNB assay was performed as described previously ${ }^{23}$. Briefly, $10 \mu \mathrm{l}$ of $\mathrm{rParg}-\mathrm{GST} \sigma$ protein $(4 \mu \mathrm{g})$ was added to a mixture containing $1 \mathrm{mM}$ GSH and different concentrations of CDNB $(0.07-8 \mathrm{mM})$ in Sodium phosphate buffer $(\mathrm{pH}-6.5)$ at room temperature and formation of GSH-CDNB conjugate was monitored spectrophotometrically by measuring the increase in absorbance at $340 \mathrm{~nm}$ for 5 minutes. Further, similar reactions with $1 \mathrm{mM} \mathrm{CDNB}$ and different concentrations of GSH (0.01-4.0 mM) were also performed. Michaelis-Menton equation and Lineweaver-Burk plot was used to deduce the specific activity ( $\mu \mathrm{mol} / \mathrm{min} / \mathrm{mg}$ of protein), $\mathrm{V}_{\max }$ and $\mathrm{K}_{\mathrm{m}}$ values of rParg-GST $\sigma$ protein against CDNB and GSH.

Optimal $p H$ determination. To determine optimum $\mathrm{pH}$ for $\mathrm{rParg}-\mathrm{GST} \sigma$ activity against CDNB, buffers of different $\mathrm{pH}$ ranging from $\mathrm{pH} 5.5$ to 11 were freshly prepared and used for CDNB assay. CDNB assay was 
performed as described above except that specific buffers of different $\mathrm{pH}$ were used. Precisely, the following mixed buffers were used: $50 \mathrm{mM}$ 2-(N-morpholino)ethanesulfonic acid/ $\mathrm{NaOH}$ for $\mathrm{pH}$ 5.5, 6.0 and 6.5; HEPES/ $\mathrm{NaOH}$ for $\mathrm{pH}$ 7.0, 7.5 and 8.0; N-[tris-9hydroxymethyl)-aminomethane for $\mathrm{pH} 8.5$ and 9.0; and 3-(cyclohexylamino)-1-propanesulfonic acid for $\mathrm{pH} 9.7,10.0$ and 11.0 as described previously ${ }^{43}$. The observed activities of rParg-GST $\sigma$ with CDNB at different $\mathrm{pH}$ were plotted against respective $\mathrm{pH}$ for determining the $\mathrm{pH}$ optima.

Peroxidase activity and 4-HNE assay. 4-HNE is an intermediate product of lipid peroxidation, and very toxic to cells in high amount. 4-HNE is not produced from direct DDT metabolism, rather produced during the lipid peroxidation, which is generally aggravated by increase in stress. Apart from detoxifying electrophilic xenobiotics, GST can also participate in glutathione-mediated detoxification (peroxidation) of reactive hydroxyl radicals and 4-HNE. Thus, to explore the potential role of rParg-GST $\sigma$ protein in mediating similar functions in sand fly during oxidative stress, peroxidase and 4-HNE activities of purified rParg-GST $\sigma$ protein were investigated. Briefly, $4 \mu \mathrm{g}$ purified $\mathrm{rParg}-\mathrm{GST} \sigma$ protein was added to a mixture containing $1 \mathrm{mM} \mathrm{GSH}$ and different concentrations of 4-HNE (10-100 $\mu \mathrm{M})$ in sodium phosphate buffer and formation of GSH-4-HNE adduct was monitored spectrophotometrically by measuring increase in absorbance at $224 \mathrm{~nm}$ for $5 \mathrm{~min}^{44,45}$. For peroxidase activity assay, $4 \mu \mathrm{g}$ purified rParg-GST $\sigma$ protein was added to a mixture containing $0.2 \mathrm{mM}$ NADPH, $1 \mathrm{U}$ glutathione reductase, $1 \mathrm{mM}$ GSH, $1 \mathrm{mM}$ EDTA and different concentrations of cumene hydroperoxide $(0.08-1.0 \mathrm{mM})$ were assayed in sodium phosphate buffer. Peroxidase activity of GST was monitored by measuring the decrease in absorbance at $340 \mathrm{~nm}$ for 5 minutes ${ }^{10,21,46}$.

Enzyme thermostability assay. The thermostability of GST $\sigma$ may have implications for heat stress tolerance capacity of sand fly, especially in high temperature conditions. Thus, the thermostability of rParg-GST $\sigma$ was evaluated by modifying the incubation temperature of CDNB assay. Precisely, rParg-GST $\sigma$ protein was mixed with CDNB assay reaction mixture and incubated at four different temperatures viz. $20^{\circ} \mathrm{C}, 35^{\circ} \mathrm{C}, 45^{\circ} \mathrm{C}$ and $55^{\circ} \mathrm{C}$ for 30 minutes along with blank control (CDNB reaction mixture without protein). The temperature range was chosen based on the annual temperature variations observed in the sand fly habitat of our study site. The activity was plotted as $\triangle \mathrm{Abs} 340 \mathrm{~nm} / \mathrm{min} / \mathrm{mg}$ protein through Graph Pad Prism software.

Dehydrochlorinase activity. Dehydrochlorination of toxic DDT insecticide yields non-toxic metabolite DDE and this conversion has been reported to be mediated by some classes of GST in insects with relevance to DDT resistance ${ }^{27,47}$. Thus, to delineate the role of sigma class GST protein in DDT to DDE conversion in sand fly, dehydrochlorinase activity of rParg-GST $\sigma$ was assessed according to the protocol described previously ${ }^{48}$. Briefly, $4.0 \mu \mathrm{g}$ rParg-GST $\sigma$ was incubated with different concentrations of DDT $(0-200 \mu \mathrm{g} / \mathrm{ml}$, dissolved in methanol) in $1 \mathrm{ml}$ reaction mixtures containing $20 \mathrm{mM}$ sodium phosphate buffer ( $\mathrm{pH} 7.6$ ), $20 \mathrm{mM} \mathrm{NaCl}$ and $2 \mathrm{mM} \mathrm{GSH}$, at $28^{\circ} \mathrm{C}$ for $2 \mathrm{hrs}$. In parallel, control reaction comprising the same reaction mixture without insecticide was also set up in triplicate. After incubation, the reaction mixtures were extracted twice with chloroform and evaporated under gentle stream of nitrogen gas until dry. The dried residue was dissolved in $300 \mu \mathrm{l}$ methanol and run on HPLC on a reverse-phase $\mathrm{C} 18$ column (Agilent ZORBAX $300 \mathrm{SB}-\mathrm{C} 18$ ) at $23-25^{\circ} \mathrm{C}$. A mixture of acetonitrile/water $90: 10$ was used as mobile phase at a flow rate of $1.0 \mathrm{ml} \mathrm{min}^{-1}$. Peaks were detected at $232 \mathrm{~nm}$ with the ultimate 3000 UV detector (Dionex) and analyzed with Dionex Chromeleon Software. The quantity of DDT and DDE were calculated using a standard curve prepared by running known concentrations of DDT \& DDE on HPLC under identical conditions. The DDT resistant sand fly homogenate was used to investigate dehydrochlorination activity in $P$. argentipes.

Quantitative RT-PCR for Parg-GST $\sigma$. Total RNA was isolated from laboratory reared single P. argentipes DDT exposed and non-exposed resistant and susceptible $P$. argentipes by using Qiagen total RNA isolation Kit. The cDNA was synthesized from $1.0 \mu \mathrm{g}$ of isolated RNA using RevertAid First Strand cDNA Synthesis kit (Thermo Fisher) through random hexamer primers. Primers for real-time PCR were designed using the Parg-GST $\sigma$ gene sequence deduced from this study. The primers used were forward 5'-CACTGAGAAATATCCCAACCTCA-3' and reverse 5'-TTAAACTTCAGTAACAGGTCGTTTC-3'. Real-Time PCR reaction was performed on a Qiagen multiplex RT-PCR and the relative expression and fold change was calculated according to the $2^{-\Delta \Delta \mathrm{CT}}$ method, incorporating PCR efficiency ${ }^{49}$ after normalization with the housekeeping gene $28 \mathrm{~s}$ rRNA.

Generation of polyclonal antibody. For identification and relative quantification of Parg-GST $\sigma$ protein in sand fly lysates for immunoblot studies, polyclonal antibody against rParg-GST $\sigma$ protein was raised in mice as described previously ${ }^{50}$ with slight modification. rParg-GST $\sigma$ protein $60 \mu \mathrm{g}$ was mixed with Freund's adjuvant and injected in the peritoneal space of 4 mice. Subsequently, two booster doses with Freund's incomplete adjuvant were administered to each mouse at two weeks interval. Two weeks after the final immunization, antibodies titre was checked by ELISA, and then the mice were sacrificed and antisera were separated from the collected blood. The antisera were incubated with immobilized $E$. coli lysate (pierce) for $2 \mathrm{hrs}$ at $4^{\circ} \mathrm{C}$ on a shaker. After incubation, the samples were centrifuged, anti-sera aspirated and stored at $4^{\circ} \mathrm{C}$ in small aliquots.

Immunoblotting for detection of GST $\sigma$ in single $P$. argentipes. Single $P$. argentipes female was macerated in $30 \mu \mathrm{l}$ of modified RIPA buffer using a hand-held homogenizer. The completely homogenized mixture was then centrifuged for $25 \mathrm{~min}$ at $13000 \mathrm{rpm}$ at $4{ }^{\circ} \mathrm{C}$ and supernatant was collected and stored in autoclaved $1.5 \mathrm{ml}$ vials. Protein concentration was estimated by Bradford assay as mentioned earlier and equal amount of protein $(0.7 \mu \mathrm{g})$ of each sand fly was resolved on 10\% SDS-PAGE and immunoblotted on to a nitrocellulose membrane $(0.4 \mu \mathrm{m})$ using semidry Trans blot apparatus (Bio-Rad). The membrane was probed with primary anti-rParg-GST $\sigma$ polyclonal antibody (1:2000) raised in mice and HRP conjugated rabbit anti-mice IgG (GeNie, 


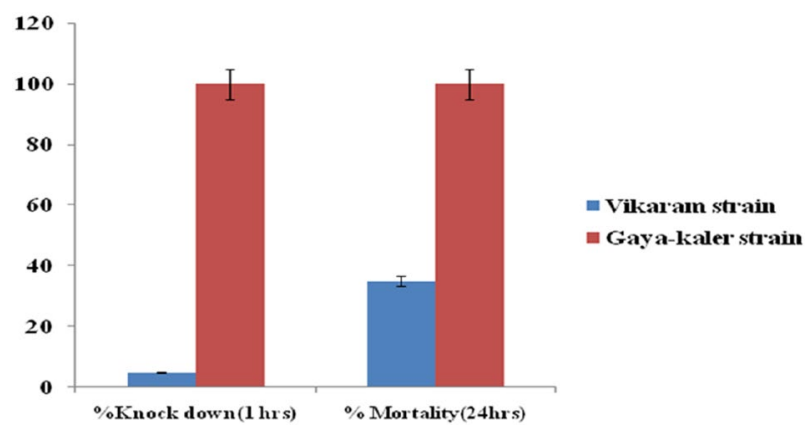

Figure 1. Susceptibility assay of Phlebotomus argentipes sandflies collected from village Vikaram (Patna) and Kaler (Gaya) was performed by Tube Bio-assay after exposure to 4\% DDT. The Kaler colony showed $100 \%$ mortality within 24 hrs (Brick red bar).

1:2000) as secondary antibody. The blot was developed with $\mathrm{DAB} / \mathrm{H}_{2} \mathrm{O}_{2}$ solution (Bio-RAD) using $0.1 \mathrm{M}$ imidazole as colour enhancer ${ }^{51,52}$. Image acquisition was performed on gel documentation machine (Gel Doc XR+, Bio-RAD).

Stress induction assay. Stress-induced elevation in GST protein expression plays important role in stress redressal and survival of insects in the hostile environmental conditions including pesticide exposure. So, the modulation of Parg-GST $\sigma$ protein expression in sand flies exposed to different stress conditions viz. different temperatures (temperature stress), $\mathrm{H}_{2} \mathrm{O}_{2}$ (oxidative stress) and DDT (pesticide stress), were investigated through immuno-blot assays. For each assay, 6 freshly emerged female adult $P$. argentipes from each group were used in triplicate. For temperature stress assay, DDT resistant female $P$. argentipes $(n=6)$ were transferred to Hilton pots \& pre-equilibrated at three temperatures viz. $4^{\circ} \mathrm{C}, 37^{\circ} \mathrm{C}$ and $55^{\circ} \mathrm{C}$ and incubated for further $25 \mathrm{~min}$ in order to avoid their early deaths at $4^{\circ} \mathrm{C}$ in BOD incubators. The time duration of $25 \mathrm{~min}$ was chosen only to collect live $P$. argentipes from $4{ }^{\circ} \mathrm{C}$ treatment group. After exposure, live $P$. argentipes individual samples were immediately processed for protein extraction and immunoblotting analysis. For $\mathrm{H}_{2} \mathrm{O}_{2}$ stress experiment, DDT resistant female $P$. argentipes were released in separate Hilton pots containing sterile cotton balls hanging from the lid and soaked with $30 \% \mathrm{H}_{2} \mathrm{O}_{2}$ and then left for $60 \mathrm{~min}$ along with control Hilton pot containing cotton ball soaked with autoclaved $\mathrm{H}_{2} \mathrm{O}$ only. After $60 \mathrm{~min}$, total protein was immediately extracted from each female P. argentipes at $4^{\circ} \mathrm{C}$ and immunoblot analysis was done as above. For DDT stress tolerance study, the DDT resistant female P. argentipes were exposed to DDT for 30 \& $60 \mathrm{~min}$ in Bio-assay tube along with unexposed control tubes having organochlorine control. For comparative evaluation of differential Parg-GST $\sigma$ protein expression in DDT exposed and unexposed susceptible vs DDT resistant $P$. argentipes, similar bioassay procedure was followed except that the exposure time in Bio-assay tube was fixed at $40 \mathrm{~min}$ to allow collection of only live P. argentipes from susceptible colony. The total protein was extracted individually from each female $P$. argentipes $(n=4)$ of all groups and immunoblot analysis was performed as mentioned earlier ${ }^{52}$. For quantification of GST $\sigma$ band, the densitometry analysis of blots was done using ImageJ analysis software (imagej.nih.gov).

Measurement of protein carbonylation by immunoblotting. Free oxidative radicals accumulated during oxidative stress can oxidize the amino acid residues of proteins to generate carbonyl groups ${ }^{53}$. Thus, protein carbonylation assay is used to comparatively evaluate the oxidative stress level. To compare the oxidative stress level generated after DDT exposure in susceptible vs resistant female $P$. argentipes, protein carbonylation assay was performed using Dinitrophenyl hydrazine (DNPH) as described previously ${ }^{54}$. Briefly, $6 \mu \mathrm{g}$ total proteins was mixed with DNPH $(1 \mathrm{mM})$ in $2 \mathrm{mM} \mathrm{HCl}$ and incubated for $20 \mathrm{~min}$ at room temperature to form carbonyl derivative dinitrophenylhydrazone. The reaction mixture was separated on a 10\% SDS-PAGE and immunoblotted on to a nitrocellulose membrane. The membrane was probed with anti-DNPH antibody (Sigma-Aldrich, 1:2000) raised in rabbit and HRP conjugated goat anti-rabbit IgG (GeNie, 1:2000) as secondary antibodies. The blot was developed with $\mathrm{DAB} / \mathrm{H}_{2} \mathrm{O}_{2}$ solution (Bio-RAD) by standard protocol as described earlier ${ }^{55}$.

Statistical analysis. Statistical analysis was carried out using GraphPad Prism 5.0 software (GraphPad Software Inc., La Jolla, CA, USA). Student's $t$-test was used to estimate the statistical significance of the differences between groups. Differences between groups were considered statistically significant when $\mathrm{p}$ value was less than 0.05 .

\section{Results}

Establishment of $100 \%$ DDT resistant and susceptible colony of $P$. argentipes by Tube Bioassay. Generating a resistant colony of $P$. argentipes is not much troublesome as it has developed DDT resistance to various extents in almost all the endemic districts of Bihar; and has been reported in previous study ${ }^{40}$. However, it is difficult to get $100 \%$ susceptible $P$. argentipes in field from India. Thus, to find DDT susceptible sandfly, we selected Kaler village of Gaya district because DDT or other insecticide was not used here in IRS for at least more than 5 years. The tube bio-assay results showed that $P$. argentipes from Kaler region is $100 \%$ susceptible to $4 \%$ DDT with complete knockdown effect observed in $60 \mathrm{~min}$ (Fig. 1). In contrast, the resistant colony was 


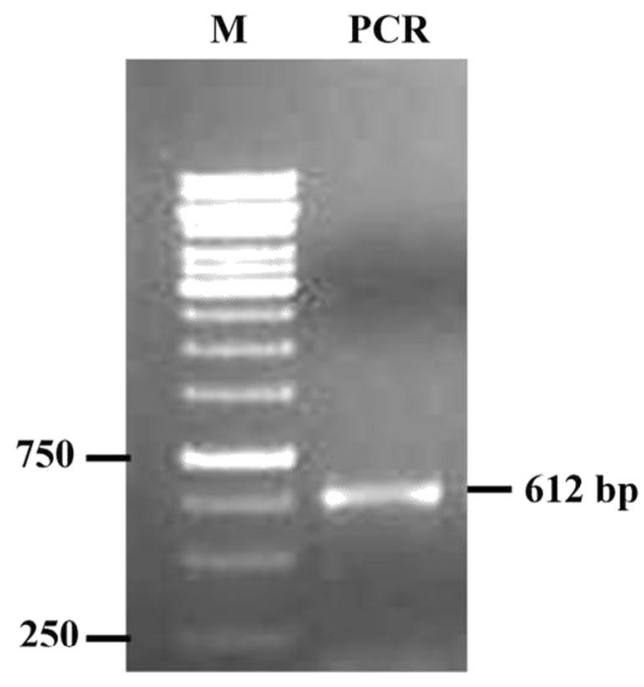

Figure 2. PCR product run on $1 \%$ agarose gel showing Lane $11.0 \mathrm{~kb}$ DNA marker; Lane 2 band of $612 \mathrm{bp}$ corresponding to Parg-GST $\sigma$ gene.

established from Vikaram village, Patna District, as there was no history of other insecticide spray except DDT in this area. The tube bio-assay on P. argentipes from Vikaram village showed $0 \%$ knockdown to $4 \%$ DDT in 60 min and exhibited more than $60 \%$ DDT resistance after $24 \mathrm{hrs}$ of recovery period (Fig. 1). The 100\% pure resistant population of $P$. argentipes from Vikaram was further reared at our institutional laboratory and obtained $100 \%$ resistant colony in the $7^{\text {th }}$ generation. Both the strains were reared separately in laboratory throughout this study.

Amplification of Parg-GST $\sigma$ gene. At the time of this study, the genome sequence of $P$. argentipes was not available and the GST-encoding gene sequence of $P$. argentipes is still uncharacterized. Thus, we used the publicly available complete cDNA sequence of GST $\sigma$ of $P$. papatasi as the template to design primers for amplification of GST $\sigma$ gene of $P$. argentipes. PCR amplification with designed primers showed a single band of $\sim 612 \mathrm{bp}$ as visualized on a $1 \%$ agarose gel stained with ethidium bromide (Fig. 2). Sequencing of $612 \mathrm{bp} \mathrm{PCR} \mathrm{product} \mathrm{and} \mathrm{BLAST}$ analysis identified the amplified product as GST $\sigma$ gene. The PCR product was then cloned and sequencing of several clones revealed a single sequence of GST $\sigma$ having $91 \%$ and $81 \%$ identity with P. papatasi and L. longipalpis GST $\sigma$ gene (Fig. 3) in Blastx search and Clustal W analysis. The gene sequence was submitted to GenBank and the accession number was obtained (Accession: MG431969).

Purification of rParg-GST $\sigma$ protein. To obtain rParg-GST $\sigma$ fusion protein, $612 \mathrm{bp}$ PCR product of GST $\sigma$ gene was cloned in pET28a expression vector and positive clone was transformed in BL21 E. coli competent cells. The expression was induced with $1 \mathrm{mM}$ IPTG and confirmed by western blotting with anti-His antibody (1:4000, G-Biosciences) (data not shown). The purification of rParg-GST $\sigma$ using $\mathrm{Ni}^{+2}$-NTA agarose beads showed a single band of $\sim 26 \mathrm{kDa}$ (including Histidine tag $3.52 \mathrm{kDa}$ ) in the elute fraction on $12 \%$ SDS-PAGE confirming that the rParg-GST $\sigma$ is expressed in soluble form (Fig. 4) which is considered ideal for enzyme activity assays.

Enzyme kinetic of rParg-GST $\sigma$ proteins. GSH \& CDNB reactivity. CDNB and DCNB are the colorimetric universal substrates of GST and are also utilized in biochemical assays for the determination of GST elevation in resistant insects ${ }^{38,55}$. So, rParg-GST $\sigma$ was initially characterized with these substrates. The enzyme kinetic analysis was conducted with various concentrations of CDNB, DCNB and GSH (mM) as per the protocol given in Methodology. The $\mathrm{K}_{\mathrm{m}}$ values of rParg-GST for CDNB \& GSH were found to be $0.39 \mathrm{mM} \& 0.13 \mathrm{mM}$ of protein, respectively. However, Vmax for CDNB \& GSH were found to be $1.39 \mathrm{mM} / \mathrm{min} / \mathrm{mg}$ and $68.92 \mathrm{mM} / \mathrm{min} / \mathrm{mg}$ of protein respectively, as deduced from Michaelis-Menton and Lineweaver-Burk plot analysis in Graph Pad Prism software. The specific activity of rParg-GST $\sigma$ at equimolar concentration $(0.8 \mathrm{mM})$ of CDNB and GSH $(0.8 \mathrm{mM})$ was found to be $8.75 \mu \mathrm{M} / \mathrm{min} / \mathrm{mg} \& 72.5 \mu \mathrm{M} / \mathrm{min} / \mathrm{mg}$ of protein, respectively (Fig. 5a,b) (Table 1).

rParg-GST $\sigma$ reactivity against 4-HNE. 4-HNE is the by-product of lipid peroxidation (LPO) $)^{56,57}$ and toxic to cells in high amount. The rParg-GST $\sigma$ was found to be highly active against 4-HNE exhibiting Km \& Vmax values of $5.02 \mu \mathrm{M} \& 19.57 \mu \mathrm{M} / \mathrm{min} / \mathrm{mg}$ of protein, respectively (Fig. 5c). The deduced specific activity of rParg-GST $\sigma$ against $4-\mathrm{HNE}$ was found to be $203.92 \mu \mathrm{M} / \mathrm{min} / \mathrm{mg}$ of protein (Table 1 ).

Peroxidase activity assay. Peroxidase activity is an important attribute for stress redressal caused by ROS ${ }^{58}$. Thus, we explored the peroxidase activity of $\mathrm{rParg}-\mathrm{GST} \sigma$ of $P$. argentipes against cumene hydroperoxide, and found that it has high affinity to cumene hydroperoxide exhibiting $\mathrm{Km} \& \mathrm{Vmax}$ values of $0.18 \mathrm{mM} \& 4.48 \mathrm{mM} / \mathrm{min} / \mathrm{mg}$, respectively (Fig. 5d). The deduced specific activity of rParg-GST $\sigma$ against cumene hydroperoxide was found to be $92.47 \mathrm{mM} / \mathrm{min} / \mathrm{mg}$ of protein (Table 1). Interestingly, rParg-GST $\sigma$ exhibited high activity for cumene hydroperoxide, as compared to recombinant Delta class GSTs from Anopheles gambiae (e.g., AgGSTD1-5 and AgGSTD1-6) ${ }^{21}$ 


\begin{tabular}{|c|c|}
\hline L. Longi & ATGCCCAACTACAAAGTGATCTACTTCAATGTGAAAGCCCTGGCTGAGCCACTGCGCTTCC \\
\hline P.arg & ATGCCCAACTACAAAGTGATCTACTTCAATGTTAAGGCTCTGGCCGAGCCTCTTCGTTTCC \\
\hline P.pap & 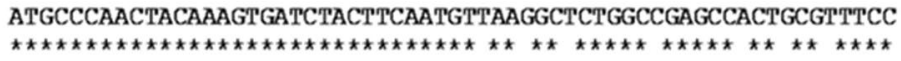 \\
\hline L. longi & TCTTGGCATATGGTGGCATTGAATTTGAGGATCTGCGCGTATCACGCGAAGAATGGCCCAC \\
\hline P.arg & TCTTGGCCTATGGTGGCATTGAATTCGAGGATCTGCGTGTATCACGCGAAGAGTGGCCCAC \\
\hline P.pap & 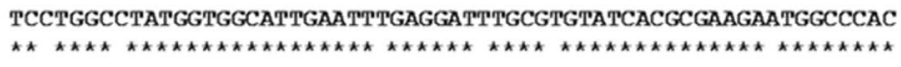 \\
\hline L.longi & CCTAAAGTCCTCTATGCCAATGGGCCAGATGCCCGTGCTGGAAGTAGATGGACGACGAGTT \\
\hline P.arg & CCTCAAGTCCTCCATGCCGATGGGCCAGATGCCCGTGCTGGAAGTGGACGGACGACGAGTT \\
\hline P.pap & 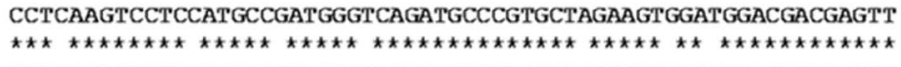 \\
\hline L. longi & CATCAGAGCATTTCAATGGCACGCTACCTGGCGAAGCAAGTGGGTCTCGTTGGTTCCGATG \\
\hline P.arg & CACCAGAGCATTTCGATGGCGCGCTACCTGGCGAAGCAAGTGGGTCTCGTTGGGGCGGACG \\
\hline P.pap & 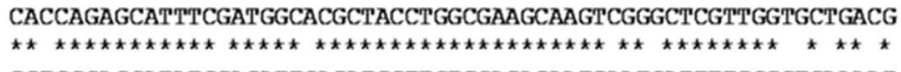 \\
\hline L.longi & CGTGGGAGGATATGCAGATTGACATCGTTGTCGACACAATCAATGATTTTCGCCTCAAAAT \\
\hline P.arg & CGTGGGAGGACATGCAGATCGACATCGTGGTGGACACAATCAGTGACTTCCGCCTCAAGAT \\
\hline P.pap & $\begin{array}{l}\text { CGTGGGAGGATCTGCAAATTGACATTGTGGTGGATACAATCAATGACTTCCGCCTCAAAAT } \\
\text { T. }\end{array}$ \\
\hline L. longi & CGCCGTCGTTPCCTACGAGCCCGATGATGATGTGAAGGAGAAGAAGTTGGTCACACTCAAC \\
\hline P.arg & CGCCGTCGCCTCGTACGAGCCCGATGATGATGTGAAGGAGAAGAAGCTGGTCACACTCAAC \\
\hline P.pap & 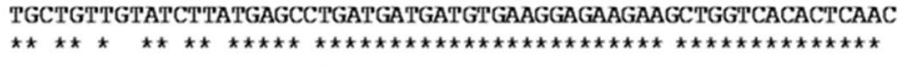 \\
\hline L. longi & AACGAAGTCATTCCCTPCTACCTGGAAAAGCTCGATTCGATCGCCAAGGAGAATAAGGGAC \\
\hline P.arg & AACGAAGTCATTCCCTTCTACCTGGAGAAGCTGGACGTGATCGCCAGGGAGAACAAGGGAC \\
\hline P.pap & 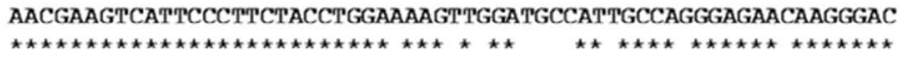 \\
\hline L. longi & ACTTTGCATTGGGAAAGCTCACATGGGCTGACCTCTACTTTGCCGGCATCCTCGATTACCT \\
\hline P.arg & АCTTCGCCCTCGGCAAGCTCACGTGGGCCGACCTGTACTTCGCCGGCATCATCGACTACCT \\
\hline P.pap & 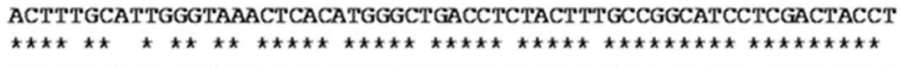 \\
\hline L. longi & CAACTACATGACCAAGACCGACCTCACGGAAAAGTACCCCAATCTCAAGGCCGTTGTGGAC \\
\hline P.arg & CAATTACATGACCAAGACCGACCTCACTGAGAAGTACCCCAACCTCAAGGCCGTGGTGGAC \\
\hline P.pap & 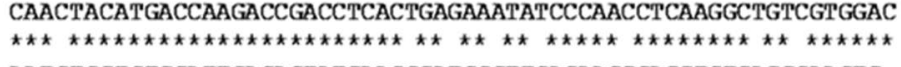 \\
\hline L. longi & AATGTGCTGTCCATTGAGAGTATCAAGGCATGGGTTGAGAAGCGACCTGTCACCGAAGTC \\
\hline P.arg & AACGTGCTGGCCATCGAGAGCATCAAGGCCTGGGTGGAGAAACGACCTGTTACTGAAGTT \\
\hline P.pap & 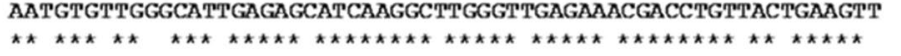 \\
\hline L. longi & TAA \\
\hline P .arg & TAA \\
\hline P.pap & TAA \\
\hline
\end{tabular}

Figure 3. Multiple nucleotides sequences alignment of Parg-GST $\sigma$ genes by Clustal W: Nucleotides sequence alignment analysis of $P$. argentipes Parg-GST $\sigma$ gene sequence shows $91 \%$ and $82 \%$ homology with sigma class GST from P. papatasi \& L. longipalpis, respectively. Identical nucleic acid residues among all species are depicted with asterisk at the base.

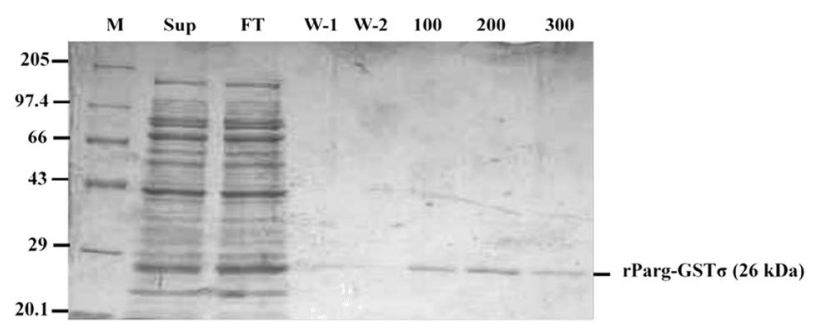

Figure 4. Purification of recombinant Parg-GST $\sigma$ protein using Ni-NTA column. All protein samples were processed and run on $12 \%$ SDS-PAGE to evaluate recombinant protein purification. Lane 1- Mol. Wt. Marker; Lane 2- Supernatant; Lane 3- Flow through; Lane 4 \&5- Wash 1 \& 2; Lane 6 to 8- elute 100, 200 \& $300 \mathrm{mM}$ imidazole, respectively.

and D. melanogaster (e.g., DmGSTD1 and DmGSTD21) ${ }^{10}$. Hence, these findings suggest that Parg-GST $\sigma$ may play a role in cellular-antioxidative defence against oxidative damage induced by DDT and other xenobiotics.

Inhibitor assay. Ethacrynic acid (EA) is an inhibitor of GSTs and well reported in several previous studies ${ }^{36}$. So, to check whether EA also inhibits the Parg-GST $\sigma$ as well as to get a mechanistic insight into the inhibition 
a)

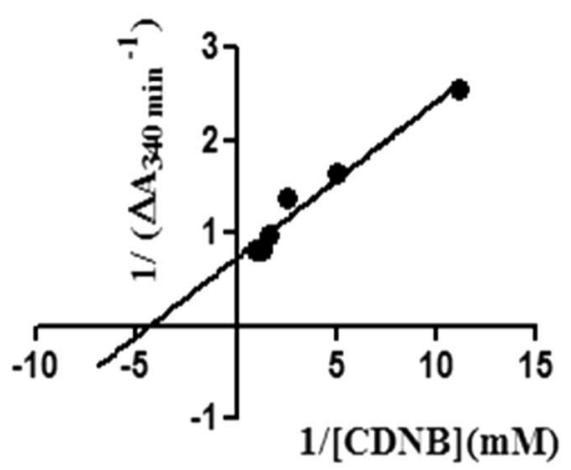

c)

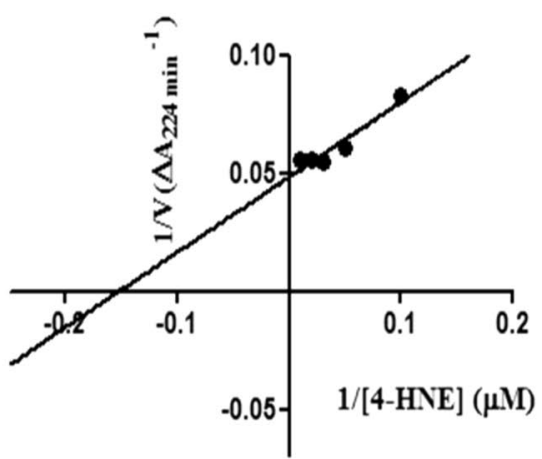

e)

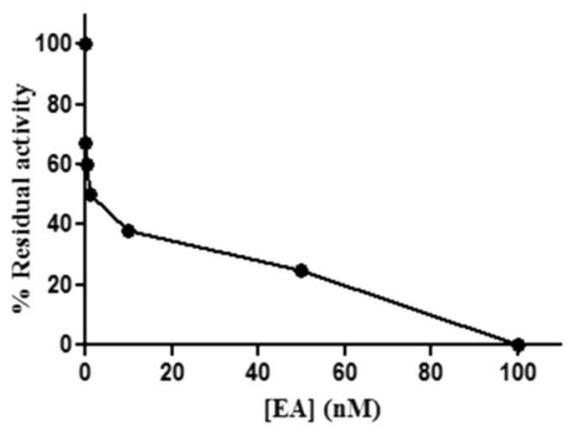

b)

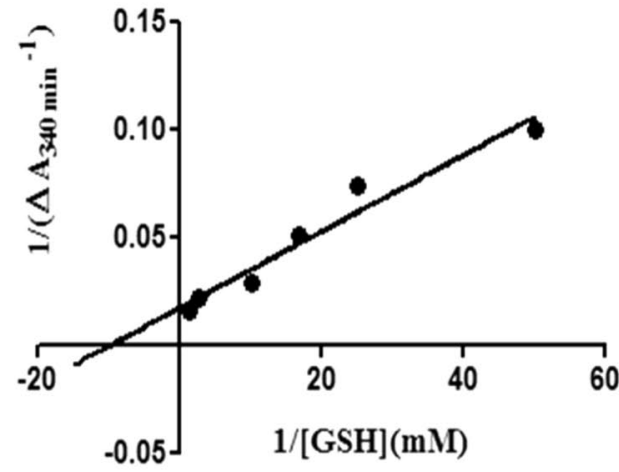

d)

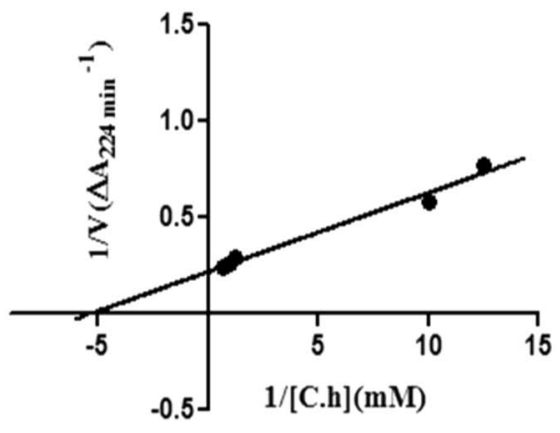

Figure 5. Enzyme kinetics analysis of Parg-GST $\sigma$ : (a) Activity of rParg-GST $\sigma$ with different concentrations of CDNB; (b) Activity of rParg-GST $\sigma$ with different concentrations of GSH; (c) rParg-GST $\sigma$ reactivity with 4-HNE; (d) Activity of rParg-GST $\sigma$ with different concentrations of cumene hydroperoxide shown as reciprocal plot; (e) \% Residual activity of rParg-GST $\sigma$ with Ethacrynic acid; (f) rParg-GST $\sigma$ activity at different temperature.

reaction, kinetic study with different concentrations of EA was performed. The inhibition assay of rParg-GST $\sigma$ with EA showed decrease in residual activity with increasing concentration of EA. The $\mathrm{IC}_{50}$ of EA against rParg-GST $\sigma$ activity was $50 \mathrm{nM}$, whereas, complete inhibition of rParg-GST $\sigma$ activity was observed at $0.1 \mu \mathrm{M}$ (Fig. 5e).

pH \& Temperature. $\quad \mathrm{pH}$ is an important determinant for the proper function of enzymes. So, to determine the optimum $\mathrm{pH}$, rParg-GST $\sigma$ activity was assayed in buffer of different $\mathrm{pH}$ and substrate CDNB concentration as given in the methodology section. The optimum GST activity was observed at pH 6.5 and it decreased 


\begin{tabular}{|l|c|l|c|}
\hline Substrate & Vmax & $\mathbf{K m}$ & $\begin{array}{l}\text { Specific Activity } \\
(\boldsymbol{\mu} \mathbf{M} / \mathbf{m i n} / \mathbf{m g})\end{array}$ \\
\hline CDNB $(\mathrm{mM})$ & 1.7 & 0.39 & 8.75 \\
\hline GSH $(\mathrm{mM})$ & 68.92 & 0.13 & 72.5 \\
\hline 4-HNE $(\mu \mathrm{M})$ & 19.57 & 5.02 & 203.92 \\
\hline Cumene hydroperoxide $(\mathrm{mM})$ & 4.48 & 0.18 & 92.47 \\
\hline
\end{tabular}

Table 1. Kinetic analysis of rParg-GST $\sigma$ : Vmax, Km and Specific Activity ( $\mu \mathrm{M} / \mathrm{min} / \mathrm{mg}$ ) of rParg-GST $\sigma$ with different substrates (CDNB, GSH, 4-HNE \& cumene hydroperoxide).

gradually with increase or decrease of $\mathrm{pH}$. Optimum temperature is also an important parameter for enzyme activity, specially for cold blooded organisms such as $P$. argentipes and the steep variation in average temperature observed during various seasons in Eastern India (ranging from $14^{\circ} \mathrm{C}$ in winter to $45^{\circ} \mathrm{C}$ in summer), the correlation between GST activity and temperature may assume pertinent for disease transmission as well as insecticide resistance. Thus, the activity of $\mathrm{rParg}-\mathrm{GST} \sigma$ was assayed at different temperatures and the results showed that the rParg-GST $\sigma$ have max temperature range from $35-45^{\circ} \mathrm{C}$ indicating its stability at higher temperature as well as perceived role in survival of sand flies during harsh temperature in summer season (Fig. 5f). Moreover, the activity of rParg-GST $\sigma$ sharply decreased at temperature beyond $45^{\circ} \mathrm{C}$ which can be clearly correlated with decrease in $P$. argentipes population during the month of June-July when the average temperature is close to $45^{\circ} \mathrm{C}$.

Induction of Parg-GST $\sigma$ in $P$. argentipes by temperature, $\mathrm{H}_{2} \mathrm{O}_{2}$ and DDT. GSTs play an important role in oxidative stress response ${ }^{32}$. The importance of stress induced defense mechanism and its role in survival of insects against pesticide have been reported in several studies ${ }^{59}$. Moreover, GST level was also found to be elevated in Nilaparvata lugens ${ }^{25}$ primarily to protect tissues by conferring resistance against oxidative damage. In our case, immuno-blotting of $P$. argentipes incubated at different temperatures revealed 2.3 fold higher expression of Parg-GST $\sigma$ at $37^{\circ} \mathrm{C}$ and 1.9 fold lower expression at $+4^{\circ} \mathrm{C}$ (Fig. 6a) indicating strong modulation of GST $\sigma$ in $P$. argentipes during temperature stress. Similarly, modulation of Parg-GST $\sigma$ expression was also observed with other stress inducers viz. $\mathrm{H}_{2} \mathrm{O}_{2}$ \& DDT exposure. Immunoblot analysis of $P$. argentipes lysates (exposed Vs non-exposed) showed 1.9 fold \& 2.0 fold higher expression of Parg-GST $\sigma$ in $30 \% \mathrm{H}_{2} \mathrm{O}_{2}$ and $4 \%$ DDT exposed $P$. argentipes, respectively, as compared to non-exposed sandflies (Fig. 6b,c). Band intensities of all the immunoblots were normalized with coomassie stained protein bands.

Thus, our results showed a vivid and strong induction of Parg-GST $\sigma$ protein expression on stress exposure supporting a stress-dependent mechanism of regulation of Parg-GST $\sigma$ protein expression that is aptly capable of alleviating stress and may ensure survival in P. argentipes.

Carbonylation assay. Proteins are the most sensitive targets of free radical species accumulated in the cells due to redox imbalance. The importance of oxidative modification of the proteins generating carbonyl groups on amino acid residues has been reported in many studies ${ }^{54,60}$. To check the ROS burden after DDT exposure in a single DDT resistant and susceptible $P$. argentipes, the carbonylation assay was conducted by western blotting of $4 \%$ DDT exposed resistant and susceptible colonies. The immunoblot probed with anti-DNP antibody showed at least 2.5 fold higher carbonylation of proteins in susceptible as compared to resistant colony (Fig. 6d) indicating higher ROS burden in susceptible colony after DDT exposure.

Quantitative real time PCR of GST in single $P$. argentipes. Previously, quantitative PCR has been used to implicate GST in pesticide resistance by determining elevation of GST gene expression in DDT and Permethrin resistant Anopheles gambiae ${ }^{61}$ and Aedes Ageypti ${ }^{26}$, respectively. To undermine the role of Parg-GST $\sigma$ in imparting DDT resistance to $P$. argentipes, relative expressions of Parg-GST $\sigma$ gene in DDT resistant and susceptible $P$. argentipes was evaluated by real time PCR. Real time PCR analysis from three separate experiments indicated that the expression of Parg-GST $\sigma$ was $2 \pm 0.2$ fold higher in DDT exposed resistant $P$. argentipes as compared to susceptible (Fig. 7a); whereas, the expression of Parg-GST $\sigma$ was found to be $1.8 \pm 0.1$ fold higher in non-exposed DDT resistant $P$. argentipes as compared to susceptible (Fig. 7b). On the other hand, similar upregulation of Parg-GST $\sigma$ was also observed in RT-PCR study of $\mathrm{H}_{2} \mathrm{O}_{2}$ and high temperature exposed sand flies. After $\mathrm{H}_{2} \mathrm{O}_{2}$ exposure, $1.4 \pm 0.1$ fold higher expression was observed in non-exposed DDT resistant and $1.6 \pm 0.1$ fold higher in exposed DDT resistant as compared to non-exposed and exposed susceptible P. argentipes, respectively (Fig. 7c). Temperature stress also induced $1.9 \pm 0.2$ fold higher expression of Parg-GST $\sigma$ gene at $37^{\circ} \mathrm{C}$ in DDT resistant as compared to susceptible P. argentipes. Although, expression of Parg-GST $\sigma$ gene was also found to be modulated at $55^{\circ} \mathrm{C}$ (Fig. $7 \mathrm{~d}$ ) but not all sandflies survived at higher temperature; no significant changes was observed at $4^{\circ} \mathrm{C}$. In conclusion, the results showed that DDT resistant sandflies have upregulated Parg-GST $\sigma$ gene expression under ambient conditions as compared to susceptible (Fig. 7d). Additionally, the resistant sandflies exhibited higher magnitude of induction of Parg-GST $\sigma$ gene under stress conditions as compared to susceptible colony which may impart enhanced stress tolerance to the resistance phenotype. Notably, inverse correlation was observed between Parg-GST $\sigma$ gene expression and ROS levels observed in carbonylation assay (Fig. 7d) under native as well as stress conditions.

Detection of differential expressions of Parg-GST $\sigma$ protein in DDT resistant and susceptible $P$. argentipes through western blotting. To validate the differential gene expression of Parg-GST $\sigma$ gene at translational level, a modified DAB-based assay was developed and employed to enable immunoblot detection 
a)

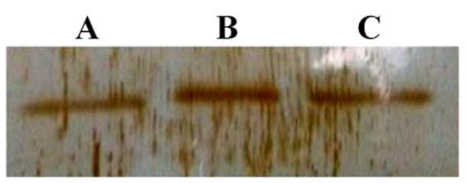

Parg-GSTo b)

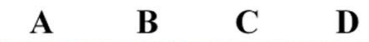

Parg-GSTo

L.C

c)

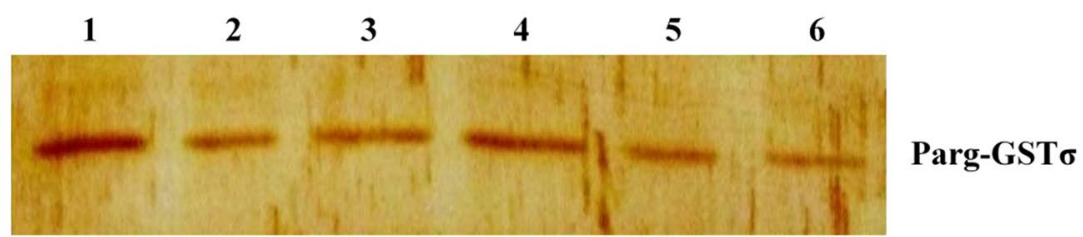

d)
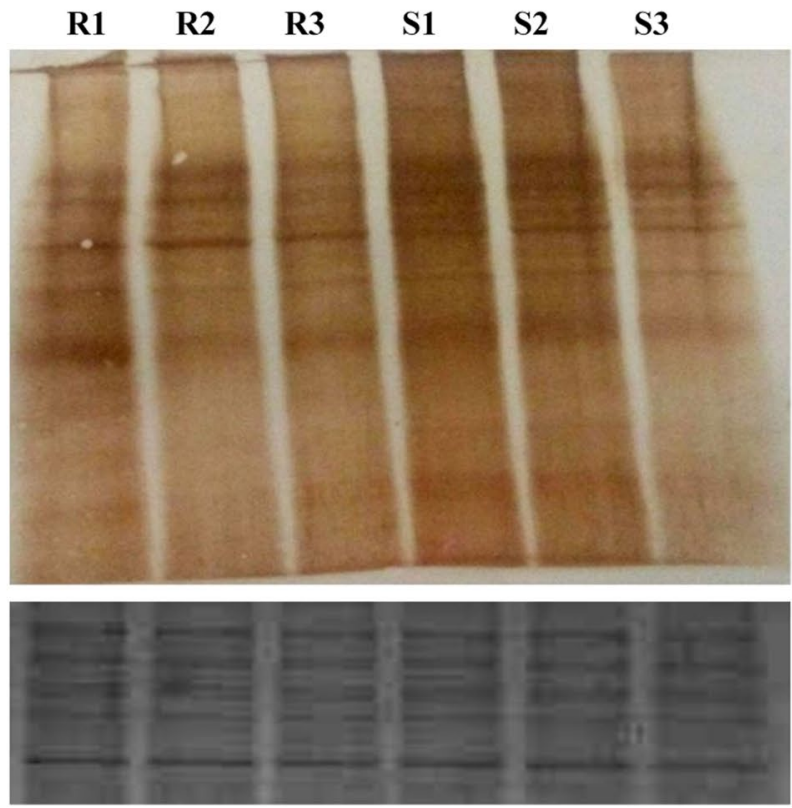

L.C

Figure 6. Immunoblot analysis showing: (a) expression of Parg-GST $\sigma$ in P. argentipes kept at different temperatures, Lane A: $+4^{\circ} \mathrm{C}$, Lane B: $+37^{\circ} \mathrm{C}$, Lane C: $+55^{\circ} \mathrm{C}$; (b) Expression of Parg-GST $\sigma$ in $\mathrm{H}_{2} \mathrm{O}_{2}$ non-exposed Vs exposed $P$. argentipes, Lane A \& B Non exposed, Lane C \& D exposed; (c) Expression of Parg-GST $\sigma$ in $4 \%$ DDT exposed Vs non-exposed P. argentipes, Lane $1 \& 4$ show: DDT exposed (60 min \& $30 \mathrm{~min}$, respectively), Lane $2 \& 3$ show: Non exposed $P$. argentipes $(60 \mathrm{~min})$, Lane $5 \& 6$ show: Non exposed $P$. argentipes (30 $\mathrm{min})$; (d) Carbonylation assay of DDT exposed resistant and susceptible $P$. argentipes shows more carbonylation in susceptible sandflies from S1-S3 in upper panel and lower panel shows loading control.

of Parg-GST $\sigma$ protein in a single sand fly. Immunoblotting assay of single resistant \& susceptible $P$. argentipes revealed 2.8 fold higher expression of Parg-GST $\sigma$ in resistant $P$. argentipes as compared to susceptible when exposed to 4\% DDT (Fig. 8a), whereas the expression of Parg-GST $\sigma$ was 2 fold higher in non-exposed DDT resistant of $P$. argentipes as compared to susceptible (Fig. 8b). Thus, these results are in concordance with results of high Parg-GST $\sigma$ gene expression in DDT resistant $P$. argentipes in RT-PCR.

Dehydrochlorinase activity. The importance of dehydrochlorinase activity in the development of DDT resistance in insects has been reported in several studies earlier ${ }^{27,47}$. Several classes of GST enzymes directly metabolize DDT through dehydrochlorination activity utilizing GSH as $\operatorname{cofactor}^{12,16}$. So, the dehydrochlorinase activity of rParg-GST $\sigma$ 
a)

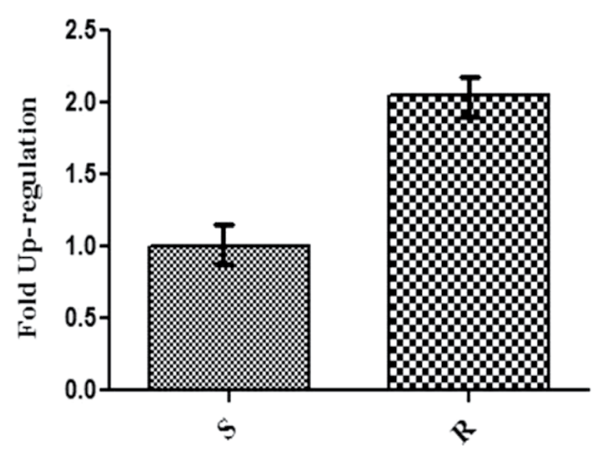

b)

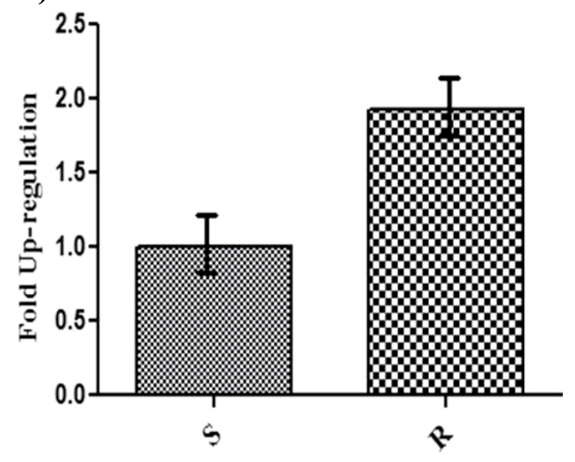

c)

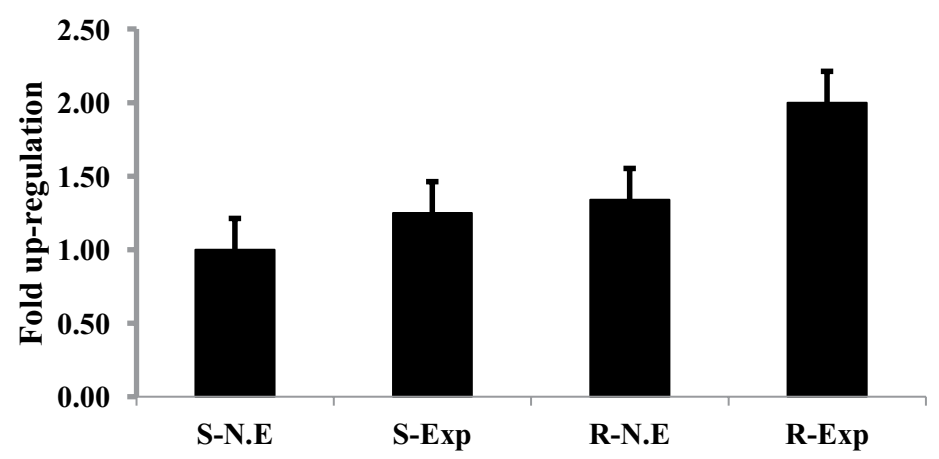

$\mathrm{H}_{2} \mathrm{O}_{2} \operatorname{exposed}(\mathrm{S}-\mathrm{Exp} \& \mathrm{R}-\mathrm{Exp}) \&$ Non exposed (S-N.E \& RN.E)

d)

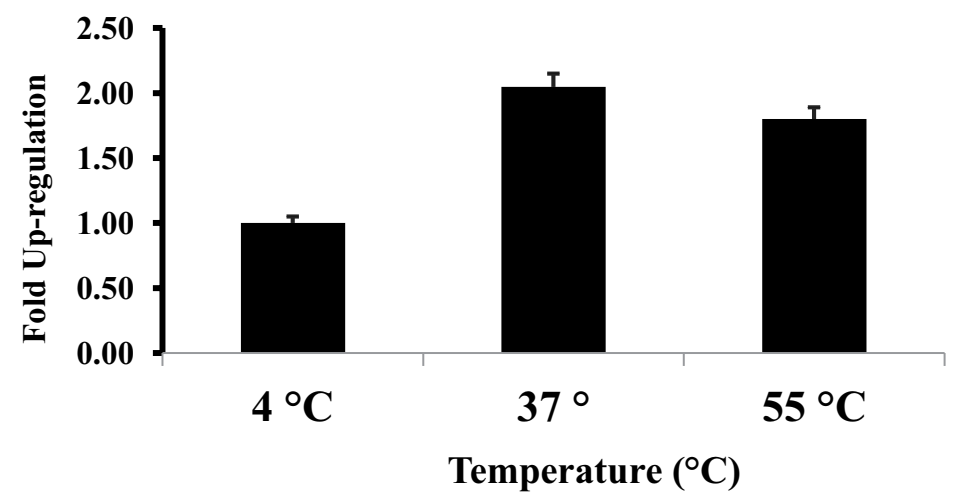

Figure 7. Quantitative PCR of Parg-GST $\sigma$ gene: (a) RT-PCR of DDT exposed susceptible (S) \& resistant (R) $P$. argentipes; (b) RT-PCR of DDT non-exposed susceptible (S) \& resistant (R) P. argentipes; (c) RT-PCR showing expression of Parg-GST $\sigma$ gene after exposure of sensitive and DDT resistant $P$. argentipes with $\mathrm{H}_{2} \mathrm{O}_{2}$ and (d) different temperatures $\left(4^{\circ} \mathrm{C}, 37^{\circ} \mathrm{C}, 55^{\circ} \mathrm{C}\right)$.

was determined using HPLC. The results showed that rParg-GST $\sigma$ doesn't have dehydrochlorination property as no significant peak of DDE was observed in HPLC graph as compared to positive control (data not shown).

\section{Discussion}

In spite of non-availability of $P$. argentipes GST gene sequence in database, we successfully cloned the sigma class GST gene and submitted its complete coding sequence (Accession no: MG431969) in the public NCBI database. The rParg-GST $\sigma$ protein was expressed, purified and characterized its enzymatic properties along with kinetic parameters. Further, we analyzed Parg-GST $\sigma$ expression profile in DDT resistant and susceptible sand fly and 
a)

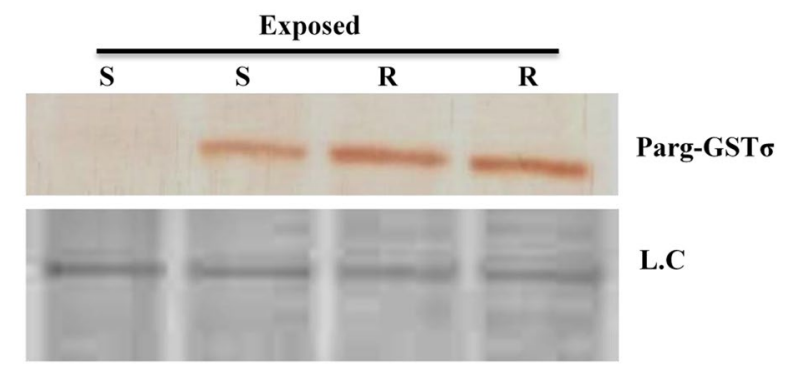

b)

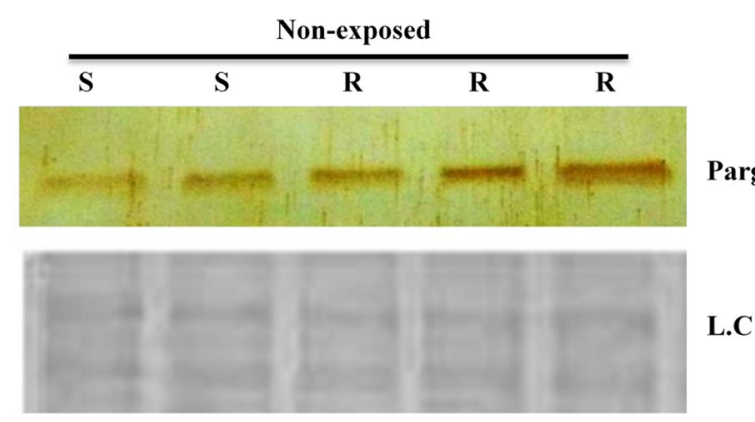

Figure 8. Immunoblot analysis showing: (a) Expression of Parg-GST $\sigma$ in DDT exposed susceptible (S) and Resistant (R) P. argentipes in upper panel; (b) Expression of Parg-GST $\sigma$ in DDT non-exposed Susceptible (S) and Resistant (R) P. argentipes in upper panel. L.C. represents loading control in both lower panels.

investigated it's potential role in reducing oxidative damage caused by DDT. We also developed a method for detection of GST protein even in single sand fly and used it to demonstrate the differential expressions of GST in DDT resistant and susceptible P. argentipes. Finally, we studied the role of Parg-GST $\sigma$ in imparting stress tolerance to these sand flies which is of potential importance in acquisition of DDT resistance.

The basis for classification of GSTs into specific class is based on percentage homology; and proteins having more than $40 \%$ identity are grouped within a single class ${ }^{62,63}$. Our BLAST results with cloned Parg-GST $\sigma$ gene sequence showed $91 \%$ and $89 \%$ identity with P. papatasi and L. longipalpis sigma class GST (Fig. 3) confirming that the GST gene reported in this study belongs to the sigma class. Several previous studies have reported that the sigma class GSTs from vertebrates and invertebrates has low but detectable activities for universal substrate $\mathrm{CDNB}^{64}$. The specific activities of sigma class GST in Drosophila have been reported to be $0.49 \mu \mathrm{M} / \mathrm{min} / \mathrm{mg}^{64}$ and $0.39 \mu \mathrm{M} / \mathrm{min} / \mathrm{mg}$ of protein $^{65}$ for CDNB substrate. However, we observed several folds higher specific activity of rParg-GST $\sigma$ sigma protein against CDNB from P. argentipes. The high specific activity against CDNB may reflect the adaptation gained to cope up with the continuous pressure exerted by DDT spray because GSTs are important detoxifying enzymes which are involved in xenobiotics detoxification including DDT ${ }^{12,66}$. However, rParg-GST $\sigma$ showed no DDT dehydrochlorination activity which reflects that its specific role is confined to cell signaling and protection against oxidative damage. Apart from that, our rParg-GST $\sigma$ activity assays performed at different $\mathrm{pH}$ showed that phosphate buffer $\mathrm{pH} 6.5$ is the appropriate buffer which should be utilized for the measurement of sigma class GST activity in $P$. argentipes whereas, Tris- $\mathrm{Cl}$ buffer $\mathrm{pH} 6.5$ completely inhibits the activity. Thus, our results extend support to the use of phosphate buffer, $\mathrm{pH} 6.5$, in GST bio-chemical assay protocol currently recommended by WHO for the detection of insecticide resistance by measuring elevation of total GST activity in insects. Interestingly, the activity assays performed at different temperatures showed that rParg-GST $\sigma$ activity increases with increase in temperature exhibiting maximum activity around $45^{\circ} \mathrm{C}$ which reflects the remarkable thermo-stability of rParg-GST $\sigma$ aptly conducive to sustain high density growth of sand flies in summer season when average maximum temperature reaches between $40^{\circ} \mathrm{C}$ to $50^{\circ} \mathrm{C}$ or even higher.

Peroxidase activity of GSTs are of particular importance in insects because, in contrast to Se-dependent peroxidase activity of glutathione peroxidase proteins, peroxidase activity of GSTs is Se-independent ${ }^{46}$; aiding in cellular anti-oxidant defense by reducing organic hydroperoxides ${ }^{67}$. In addition, sigma class GSTs also metabolize 4-HNE which is a by-product of LPO ${ }^{68}$ produced during the breakdown of long chain lipid hydroperoxides $^{69}$. In this context, the observed activity of rParg-GST $\sigma$ towards cumene hydroperoxide and 4-HNE indicates its role in antioxidant defense and metabolism of LPO by-product in P. argentipes. Earlier in D. melanogaster, GST $\sigma$ was reported to be involved in LPO pathway through its ability to catalyze the conjugation of GSH to $4-\mathrm{HNE}^{65}$. Moreover, an efficient protection against LPO by-product in sandflies may be a manifestation of higher specific activity and/or up-regulation of GST protein expression levels, either or both of which may also contribute to stress tolerance and/or insecticide resistance. The DDT resistant sandflies inherently exhibited significantly lower oxidative stress levels as compared to sensitive ones as assessed by protein carbonylation assay. The 
observed up-regulation of Parg-GST $\sigma$ protein level in DDT resistant sandflies as compared to sensitive ones and stress-induced induction of Parg-GST $\sigma$ protein expression levels strongly endorses our view that Parg-GST $\sigma$ has a protective role in acquisition of DDT resistance mediated by enhancing stress tolerance and/or activating stress redressal mechanism. Moreover, DDT spray may also force a shift in habitat of sand flies from inside house to outside as reported by Poche et al..$^{70}$, where an increase in abundance of $P$. argentipes was observed in outside vegetation area post-IRS in Bihar. This shift in habitat or increase in outdoor density increases exposure to various xenobiotics including plant based allelochemicals, which in turn can induce GSTs as reported previously in several insects ${ }^{71-75}$. In M. destructor, the larvae exposed to allelochemicals showed elevated levels of sigma and delta GST RNA in their midgut ${ }^{72}$. Thus, the DDT exposure/spray may ultimately culminate into elevated GST levels in surviving sandflies and contribute in acquisition of DDT resistance and/or stress tolerance. Indeed, Oliver et al., has recently showed that, GST plays a pivotal role in neutralizing oxidative burden in DDT resistant Anopheles mosquitoes and is found to be elevated in response to oxidative damage caused by insecticide and xenobiotics ${ }^{35}$; which further consolidates our hypothesis.

Apart from its perceived role in stress tolerance and DDT resistance, Parg-GST $\sigma$ may serve as a valuable diagnostic tool to differentiate between sensitive and DDT resistant sand flies, aided by the observed up-regulation of Parg-GST $\sigma$ in DDT resistant sand flies. Until now, this differentiation is based on total GST biochemical assay protocol recommended by WHO for mosquitoes and extended to $P$. argentipes. However, it requires skilled hands and sophisticated instruments, often difficult to realize in real-time and on the spot at field conditions. In this study, the differential expression of Parg-GST $\sigma$ was successfully detected at single sand fly level by a modified DAB-based western blotting to differentiate between DDT resistant and sensitive sand fly utilizing polyclonal anti-rParg-GST $\sigma$ antibody raised by us. Our result showed a visually discriminating difference in Parg-GST $\sigma$ protein levels between the resistant and sensitive sand flies and thus, unveiling a method of potential diagnostic importance in differentiating between DDT resistant and sensitive sand flies in the field samples of $P$. argentipes. Previously, the GST elevation in other insects has been detected by real time PCR and ELISA ${ }^{26,76}$. However, as far as our knowledge, there is no report available till date for detecting GST differential expression in single sand fly or other insects by using DAB system; which has an added advantage of being easily amenable in visible range ${ }^{77}$ with single sand fly in near future. Apart from the diagnostic perspective, our study also unveils new potential target for designing new alternative insecticide against $P$. argentipes; a domain severely lacking in the fields of vector research in $P$. argentipes, largely impeded by the unavailability of complete genome database, and is of immense importance for developing countries hosting significant leishmaniasis disease burden and transmission vector abundance including India.

Received: 29 August 2018; Accepted: 9 December 2019;

Published online: 23 December 2019

\section{References}

1. Andrade-Narvaez, F. J., Vargas-Gonzalez, A., Canto-Lara, S. B. \& Damian-Centeno, A. G. Clinical picture of cutaneous leishmaniases due to Leishmania (Leishmania) mexicana in the Yucatan peninsula, Mexico. Mem Inst Oswaldo Cruz 96, 163-167 (2001).

2. Torres-Guerrero, E., Quintanilla-Cedillo, M. R., Ruiz-Esmenjaud, J. \& Arenas, R. Leishmaniasis: a review. F1000Res 6, 750 (2017).

3. Georgiadou, S. P., Makaritsis, K. P. \& Dalekos, G. N. Leishmaniasis revisited: Current aspects on epidemiology, diagnosis and treatment. J Transl Int Med 3, 43-50 (2015).

4. NVBDCP. Annual Report on Kala-azar. (ed. N.V.B.D.C. PROGRAMME \& D.G.O.H. SERVICES) 12-13 (2014).

5. Thakur, C. P. Is elimination of kala-azar feasible by 2017? Indian J Med Res 144, 799-802 (2016).

6. Sundar, S. \& Singh, A. Recent developments and future prospects in the treatment of visceral leishmaniasis. Ther Adv Infect Dis 3, 98-109 (2016).

7. Coleman, M. et al. DDT-based indoor residual spraying suboptimal for visceral leishmaniasis elimination in India. Proc Natl Acad Sci USA 112, 8573-8578 (2015).

8. Chowdhury, R. et al. Indoor residual spraying for kala-azar vector control in Bangladesh: A continuing challenge. PLoS Negl Trop Dis 12, e0006846 (2018).

9. Gomes, B. et al. Knockdown resistance mutations predict DDT resistance and pyrethroid tolerance in the visceral leishmaniasis vector Phlebotomus argentipes. PLoS Negl Trop Dis 11, e0005504 (2017).

10. Tang, A. H. \& Tu, C. P. Biochemical characterization of Drosophila glutathione S-transferases D1 and D21. J Biol Chem 269, 27876-27884 (1994).

11. Hemingway, J. \& Ranson, H. Insecticide resistance in insect vectors of human disease. Annu Rev Entomol 45, 371-391 (2000).

12. Enayati, A. A., Ranson, H. \& Hemingway, J. Insect glutathione transferases and insecticide resistance. Insect Mol Biol 14, 3-8 (2005).

13. Wei, S. H., Clark, A. G. \& Syvanen, M. Identification and cloning of a key insecticide-metabolizing glutathione S-transferase (MdGST-6A) from a hyper insecticide-resistant strain of the housefly Musca domestica. Insect Biochem Mol Biol 31, 1145-1153 (2001).

14. Hemingway, J., Miyamoto, J. \& Herath, P. R. J. A possible novel link between organophosphorus and DDT insecticide resistance genes in Anopheles: supporting evidence from fenitrothion metabolism studies. Pesticide Biochem and Physiol 39, 49-56 (1991).

15. Bogwitz, M. R. et al. Cyp12a4 confers lufenuron resistance in a natural population of Drosophila melanogaster. Proc Natl Acad Sci USA 102, 12807-12812 (2005).

16. Clark, A. G. \& Shamaan, N. A. Evidence that DDT-dehydrochlorinase from the house fly is a glutathione S-transferase. Pesticide Biochem and Physiol 22, 249-261 (1984).

17. Shou-Min, F. Insect glutathione S-transferase: a review of comparative genomic studies and response to xenobiotics. B Insectol 65, 265-271 (2012).

18. Sanil, D., Shetty, V. \& Shetty, N. J. Differential expression of glutathione s-transferase enzyme in different life stages of various insecticide-resistant strains of Anopheles stephensi: a malaria vector. J Vector Borne Dis 51, 97-105 (2014).

19. Motoyama, N. Glutathione S-transferases: their role in the metabolism of organophosphorus insecticides. Reviews in biochem Toxicol (1980).

20. Hassan, F., Dinesh, D. S. \& Purkait, B. Bio-chemical characterization of detoxifying enzymes in DDT resistant field isolates of Phlebotomus argenitipes in Bihar, India. International Journal of Medicine and Pharmaceutical Sciences 5(2), 23-32 (2015).

21. Ranson, H., Prapanthadara, L. \& Hemingway, J. Cloning and characterization of two glutathione S-transferases from a DDTresistant strain of Anopheles gambiae. Biochem J 324(Pt 1), 97-102 (1997). 
22. Grant, D. F., Dietze, E. C. \& Hammock, B. D. Glutathione S-transferase isozymes in Aedes aegypti: purification, characterization, and isozyme-specific regulation. Insect biochem 21, 421-433 (1991).

23. Yamamoto, K., Fujii, H., Aso, Y., Banno, Y. \& Koga, K. Expression and characterization of a sigma-class glutathione S-transferase of the fall webworm, Hyphantria cunea. Biosci Biotechnol Biochem 71, 553-560 (2007).

24. Gawande, N. D., Subashini, S., Murugan, M. \& Subbarayalu, M. Molecular screening of insecticides with sigma glutathione S-transferases (GST) in cotton aphid Aphis gossypii using docking. Bioinformation 10, 679-683 (2014)

25. Vontas, J. G., Small, G. J., Nikou, D. C., Ranson, H. \& Hemingway, J. Purification, molecular cloning and heterologous expression of a glutathione S-transferase involved in insecticide resistance from the rice brown planthopper, Nilaparvata lugens. Biochem J 362, 329-337 (2002)

26. Lumjuan, N. et al. The role of the Aedes aegypti Epsilon glutathione transferases in conferring resistance to DDT and pyrethroid insecticides. Insect Biochem Mol Biol 41, 203-209 (2011).

27. Brown, A. W. Insecticide resistance in mosquitoes: a pragmatic review. J Amer Mosquito Control Associat 2, 123-140 (1986).

28. Abdollahi, M., Ranjbar, A., Shadnia, S., Nikfar, S. \& Rezaie, A. Pesticides and oxidative stress: a review. Med Sci Monit 10, RA141-147 (2004).

29. Hayaoka, T. \& Dauterman, W. C. Induction of glutathione S-transferase by phenobarbital and pesticides in various house fly strains and its effect on toxicity. Pesticide Biochem and Physiol 17, 113-119 (1982).

30. Despres, L., David, J. P. \& Gallet, C. The evolutionary ecology of insect resistance to plant chemicals. Trends Ecol Evol 22, 298-307 (2007).

31. Sawicki, R., Singh, S. P., Mondal, A. K., Benes, H. \& Zimniak, P. Cloning, expression and biochemical characterization of one Epsilon-class (GST-3) and ten Delta-class (GST-1) glutathione S-transferases from Drosophila melanogaster, and identification of additional nine members of the Epsilon class. Biochem J 370, 661-669 (2003).

32. Yan, H., Jia, H., Gao, H., Guo, X. \& Xu, B. Identification, genomic organization, and oxidative stress response of a sigma class glutathione S-transferase gene (AccGSTS1) in the honey bee, Apis cerana cerana. Cell Stress Chaperones 18, 415-426 (2013).

33. Ding, Y. et al. Characterization of the promoters of Epsilon glutathione transferases in the mosquito Anopheles gambiae and their response to oxidative stress. Biochem J 387, 879-888 (2005).

34. Udomsinprasert, R. et al. Identification, characterization and structure of a new Delta class glutathione transferase isoenzyme. Biochem J 388, 763-771 (2005).

35. Oliver, S. V. \& Brooke, B. D. The Role of Oxidative Stress in the Longevity and Insecticide Resistance Phenotype of the Major Malaria Vectors Anopheles arabiensis and Anopheles funestus. PLoS One 11, e0151049 (2016).

36. Enayati, A. A. \& Ladonni, H. Biochemical assay baseline data of permethrin resistance in Anopheles stephensi (Diptera, Culicidae) from Iran. Pakistan J. Biol. Sci 9, 1265-1270 (2006).

37. Hassan, M. M. et al. Insecticide resistance in the sand fly, Phlebotomus papatasi from Khartoum State, Sudan. Parasit Vectors 5, 46 (2012).

38. W.H.O. Test procedures for insecticide resistance monitoring in malaria vectors, bio-efficacy and persistence of insecticides on treated surfaces. In Report of the WHO Informal Consultation. (ed. Zaim, D. M./WHOPES) 28-30 September (1998).

39. Krajewski, S., Zapata, J. M. \& Reed, J. C. Detection of multiple antigens on western blots. Anal Biochem 236, 221-228 (1996).

40. Singh, R., Das, R. K. \& Sharma, S. K. Resistance of sandflies to DDT in Kala-azar endemic districts of Bihar, India. Bulletin of the World Health Organization 79, 793-793 (2001).

41. Kumar, V. et al. Insecticide susceptibility of Phlebotomus argentipes \& assessment of vector control in two districts of West Bengal, India. Indian J Med Res 142, 211-215 (2015).

42. Dinesh, D. S. et al. Insecticide susceptibility of Phlebotomus argentipes in visceral leishmaniasis endemic districts in India and Nepal. PLoS Negl Trop Dis 4, e859 (2010).

43. Ali, V., Shigeta, Y., Tokumoto, U., Takahashi, Y. \& Nozaki, T. An intestinal parasitic protist, Entamoeba histolytica, possesses a nonredundant nitrogen fixation-like system for iron-sulfur cluster assembly under anaerobic conditions. J Biol Chem 279, 16863-16874 (2004).

44. Alin, P., Danielson, U. H. \& Mannervik, B. 4-Hydroxyalk-2-enals are substrates for glutathione transferase. FEBS Lett 179, 267-270 (1985).

45. Veal, E. A., Toone, W. M., Jones, N. \& Morgan, B. A. Distinct roles for glutathione S-transferases in the oxidative stress response in Schizosaccharomyces pombe. J Biol Chem 277, 35523-35531 (2002).

46. Samra, A. I., Kamita, S. G., Yao, H. W., Cornel, A. J. \& Hammock, B. D. Cloning and characterization of two glutathione S-transferases from pyrethroid-resistant Culex pipiens. Pest Manag Sci 68, 764-772 (2012).

47. Hemingway, J. The molecular basis of two contrasting metabolic mechanisms of insecticide resistance. Insect Biochem Mol Biol 30, 1009-1015 (2000).

48. Morou, E. et al. A dehydrochlorinase-based $\mathrm{pH}$ change assay for determination of DDT in sprayed surfaces. Anal Biochem 378, 60-64 (2008)

49. Schmittgen, T. D. \& Livak, K. J. Analyzing real-time PCR data by the comparative C(T) method. Nat Protoc 3, 1101-1108 (2008).

50. Zaidi, A. et al. Interaction of frataxin, an iron binding protein, with $\mathrm{IscU}$ of $\mathrm{Fe}-\mathrm{S}$ clusters biogenesis pathway and its upregulation in AmpB resistant Leishmania donovani. Biochimie 115, 120-135 (2015).

51. Pukac, L. A., Carter, J. E., Morrison, K. S. \& Karnovsky, M. J. Enhancement of diaminobenzidine colorimetric signal in immunoblotting. Biotechniques 23, 385-388 (1997).

52. Sambrook, J., Fritsch, E. F. \& Maniatis, T. Molecular Cloning: a Laboratory Manual (Cold Spring Harbor Laboratory Press, Cold Spring Harbor, 2001).

53. Seehuus, S. C., Norberg, K., Gimsa, U., Krekling, T. \& Amdam, G. V. Reproductive protein protects functionally sterile honey bee workers from oxidative stress. Proc Natl Acad Sci USA 103, 962-967 (2006).

54. Weber, D., Davies, M. J. \& Grune, T. Determination of protein carbonyls in plasma, cell extracts, tissue homogenates, isolated proteins: Focus on sample preparation and derivatization conditions. Redox Biol 5, 367-380 (2015).

55. Singh, K. et al. Deciphering the interplay between cysteine synthase and thiol cascade proteins in modulating Amphotericin B resistance and survival of Leishmania donovani under oxidative stress. Redox Biol 12, 350-366 (2017).

56. Gard, A.L., Solodushko, V. G., Waeg, G. \& Majic, T. 4-hydroxynonenal, a lipid peroxidation by product of spinal cord Injury, is cytotoxic for oligodendrocyte progenitors and inhibits their responsiveness to PDGF. In Microscop Res and Techniq 709-718 (2001).

57. Mihalas, B. P., De Iuliis, G. N., Redgrove, K. A., McLaughlin, E. A. \& Nixon, B. The lipid peroxidation product 4-hydroxynonenal contributes to oxidative stress-mediated deterioration of the ageing oocyte. Sci Rep 7, 6247 (2017).

58. Montano, M. M., Deng, H., Liu, M., Sun, X. \& Singal, R. Transcriptional regulation by the estrogen receptor of antioxidative stress enzymes and its functional implications. Oncogene 23, 2442-2453 (2004).

59. Chakrabarti, P., Rana, S., Sarkar, S., Smith, B. \& Basu, P. Pesticide-induced oxidative stress in laboratory and field populations of native honey bees along intensive agricultural landscapes in two Eastern Indian states. Apidologie 46, 107-129 (2015).

60. Augustyniak, E. et al. Validation of protein carbonyl measurement: a multi-centre study. Redox Biol 4, 149-157 (2015).

61. Ding, Y., Ortelli, F., Rossiter, L. C., Hemingway, J. \& Ranson, H. The Anopheles gambiae glutathione transferase supergene family: annotation, phylogeny and expression profiles. BMC Genom 4, 35 (2003).

62. Hayes, J. D., Flanagan, J. U. \& Jowsey, I. R. Glutathione transferases. Annu Rev Pharmacol Toxicol 45, 51-88 (2005). 
63. Sheehan, D., Meade, G., Foley, V. M. \& Dowd, C. A. Structure, function and evolution of glutathione transferases: implications for classification of non-mammalian members of an ancient enzyme superfamily. Biochem J 360, 1-16 (2001).

64. Agianian, B. et al. Structure of a Drosophila sigma class glutathione S-transferase reveals a novel active site topography suited for lipid peroxidation products. J Mol Biol 326, 151-165 (2003).

65. Singh, S. P., Coronella, J. A., Benes, H., Cochrane, B. J. \& Zimniak, P. Catalytic function of Drosophila melanogaster glutathione S-transferase DmGSTS1-1 (GST-2) in conjugation of lipid peroxidation end products. Eur J Biochem 268, 2912-2923 (2001).

66. Panini, M., Manicardi, G. C., Moores, G. D. \& Mazzoni, E. An overview of the main pathways of metabolic resistance in insects. Invertebrate Survival J 13, 326-335 (2016).

67. Parkes, T. L., Hilliker, A. J. \& Phillips, J. P. Genetic and biochemical analysis of glutathione-S-transferase in the oxygen defense system of Drosophila melanogaster. Genome 36, 1007-1014 (1993).

68. Benedetti, A., Comporti, M. \& Esterbauer, H. Identification of 4-hydroxynonenal as a cytotoxic product originating from the peroxidation of liver microsomal lipids. Biochim Biophys Acta 620, 281-296 (1980).

69. Ayala, A., Munoz, M. F. \& Arguelles, S. Lipid peroxidation: production, metabolism, and signaling mechanisms of malondialdehyde and 4-hydroxy-2-nonenal. Oxid Med Cell Longev 2014, 360438 (2014).

70. Poche, D. M. et al. Bionomics of Phlebotomus argentipes in villages in Bihar, India with insights into efficacy of IRS-based control measures. PLoS Negl Trop Dis 12, e0006168 (2018).

71. Simon, J. Y. Insect glutathione S-transferases. Zoological Studies 35, 9-19 (1996).

72. Mittapalli, O., Neal, J. J. \& Shukle, R. H. Tissue and life stage specificity of glutathione S-transferase expression in the Hessian fly, Mayetiola destructor: implications for resistance to host allelochemicals. J Ins Sci 7, 20 (2007).

73. Abdel-Aal, Y. A. I. \& Roe, R. M. Conjugation of chlorodinitrobenzene with reduced glutathione in the absence and presence of glutathione transferase from larvae of the southern armyworm, Spodoptera eridania. Pesticide Biochem and Physiol 36, 248-258 (1990).

74. Yu, S. J. Host plant induction of glutathione S-transferase in the fall armyworm. Pesticide Biochem and Physiol 18, 101-106 (1982).

75. Wadleigh, R. W. \& Yu, S. J. Detoxification of isothiocyanate allelochemicals by glutathione transferase in three lepidopterous species. JChem Ecol 14, 1279-1288 (1988).

76. Ranson, H. et al. Identification of a novel class of insect glutathione S-transferases involved in resistance to DDT in the malaria vector Anopheles gambiae. Biochem J 359, 295-304 (2001).

77. Venkataramana, M. et al. Development of sandwich dot-ELISA for specific detection of Ochratoxin A and its application on to contaminated cereal grains originating from India. Front Microbiol 6, 511 (2015).

\section{Acknowledgements}

The authors are grateful to Gaurav Garg, Kuljit Singh, Parool Gupta of Biochemistry department for the facilitation in laboratory equipments. The authors also want to acknowledge all the technical staff of Biochemistry, Vector Biology \& control for their support. This work was supported by ICMR New Delhi and UGC-MANF for fellowship.

\section{Author contributions}

F.H., K.P.S. \& V.A. contributed to conceiving and designing experiment, running the experiments, analyzing data associated with experiments and in writing the manuscript. P.S., contributed to HPLC analysis. S.B., contributed in writing and reviewing the manuscripts. D.S.D. \& P.D. contributed for reagents, and experimental suggestions of the manuscript.

\section{Competing interests}

The authors declare no competing interests.

\section{Additional information}

Correspondence and requests for materials should be addressed to V.A. or D.S.D.

Reprints and permissions information is available at www.nature.com/reprints.

Publisher's note Springer Nature remains neutral with regard to jurisdictional claims in published maps and institutional affiliations.

Open Access This article is licensed under a Creative Commons Attribution 4.0 International License, which permits use, sharing, adaptation, distribution and reproduction in any medium or format, as long as you give appropriate credit to the original author(s) and the source, provide a link to the Creative Commons license, and indicate if changes were made. The images or other third party material in this article are included in the article's Creative Commons license, unless indicated otherwise in a credit line to the material. If material is not included in the article's Creative Commons license and your intended use is not permitted by statutory regulation or exceeds the permitted use, you will need to obtain permission directly from the copyright holder. To view a copy of this license, visit http://creativecommons.org/licenses/by/4.0/.

(c) The Author(s) 2019 